\title{
Comparison of stratospheric evolution during the major sudden stratospheric warming events in 2018 and 2019
}

\author{
Zheng Ma ${ }^{1,2,3}$, Yun Gong ${ }^{1,3 *}$, ShaoDong Zhang1,3,4, JiaHui Luo ${ }^{1,2,3}$, QiHou Zhou' ${ }^{5}$, ChunMing Huang 1,3, and \\ KaiMing Huang 1,3 \\ ${ }^{1}$ School of Electronic Information, Wuhan University, Wuhan 430072, China; \\ ${ }^{2}$ State Key Laboratory of Space Weather, Chinese Academy of Sciences, Beijing 100190, China; \\ ${ }^{3}$ Key Laboratory of Geospace Environment and Geodesy, Ministry of Education, Wuhan 430079, China; \\ ${ }^{4}$ State Key Laboratory of Information Engineering in Surveying, Mapping and Remote Sensing, Wuhan University, Wuhan 430079, China; \\ ${ }^{5}$ Electrical and Computer Engineering Department, Miami University, Oxford, Ohio 45056, USA
}

\section{Key Points:}

- The longitudinal dependencies of the temperature-enhanced regions are related to the distribution of anticyclones in the prewarming period

- The polar vortex underwent recombination in the 2018 sudden stratosphere warming event (SSW) but splitting in the 2019 SSW in the postwarming period

- Transitions of the polar vortices were all observed over the Atlantic region in the postwarming period

Citation: Ma, Z., Gong, Y., Zhang, S. D., Luo, J. H., Zhou, Q. H., Huang, C. M., and Huang, K. M. (2020). Comparison of stratospheric evolution during the major sudden stratospheric warming events in 2018 and 2019. Earth Planet. Phys., 4(5), $493-503$.

http://doi.org/10.26464/epp2020044

\begin{abstract}
Using Modern-Era Retrospective analysis for Research and Applications, Version 2 (MERRA-2) data in the northern hemisphere at the $10 \mathrm{hPa}$ level, we compared the stratospheric evolution of temperature and geopotential height during two major sudden stratosphere warming events (SSWs) that occurred in the Arctic winter of 2018 and 2019. In the prewarming period, poleward temperature-enhanced regions were mainly located around $120^{\circ} \mathrm{E}$ with a displaced vortex and around $120^{\circ} \mathrm{E}$ and $60^{\circ} \mathrm{W}$ with splitting vortices. The evolution of geopotential height indicated that these temperature-enhanced regions were both on the western side of high-latitude anticyclones. In the postwarming period, the polar vortex turned from splitting to displacement in the 2018 SSW but from displacement to splitting in the 2019 SSW. Both transitions were observed over the Atlantic region, which may have been caused by anticyclones moving through the polar region. Our findings revealed that the evolution of the anticyclone is important during SSWs and is closely related to temperature-enhanced regions in the prewarming periods and to transitions of the polar vortices in postwarming periods.
\end{abstract}

Keywords: sudden stratosphere warming; transitions of the polar vortex; anticyclone; Atlantic region

\section{Introduction}

Sudden stratospheric warming (SSW) is a large-scale meteorological event that always occurs with the winter polar stratospheric temperature increasing sharply within several days (Matsuno, 1971; Andrews et al., 1987). This polar event is reported to have a large impact on the atmosphere and on the ionosphere at other latitudes (e.g., Ayarzagüena et al., 2011; Gong Y et al., 2013, 2016, 2018a, b; Coy and Pawson, 2015; Butler et al., 2017; Ma Z et al., 2017, 2018, 2020; Xiong JG et al., 2018; Li N et al., 2020). A major SSW event is associated with a reversal of the zonal mean zonal wind (from eastward to westward) at $10 \mathrm{hPa}$ of $60^{\circ} \mathrm{N}$ and a posit-

Correspondence to: Y. Gong, yun.gong@whu.edu.cn

Received 30 MAR 2020; Accepted 04 MAY 2020.

Accepted article online 28 JUN 2020.

(C) 2020 by Earth and Planetary Physics. ive zonal mean temperature difference between $90^{\circ} \mathrm{N}$ and $60^{\circ} \mathrm{N}$ at the $10 \mathrm{hPa}$ level. In general, the first date of the wind reversal is defined as the central date of the major SSW event. During major SSWs, the polar vortex moves southward from the North Pole or splits into two daughter vortices, which are always classified as "displacement-type SSW" events and "split-type SSW" events. The displacement-type SSWs are generally believed to be caused by strong planetary waves with a zonal wavenumber of 1 (wave 1), whereas the split-type SSWs are mainly due to the enhancement of planetary waves with a zonal wavenumber of 2 (wave 2; e.g., Charlton and Polvani, 2007; Karpechko et al., 2018; Rao J et al., 2018, 2019a, 2019b). The statistical characteristics of the planetary waves during major SSWs and the two vortex types have also been verified by modeling analyses (e.g., Cao C et al., 2019; Liu SM et al., 2019). However, the polar vortices reveal different statuses before and after the central dates during some atypical events, 
which causes discrepancies in the classification of SSW types. For instance, the 2006 SSW was defined as a displacement event by Kuttippurath and Nikulin (2012), Seviour et al. (2013), Albers and Birner (2014), and Rao J et al. (2019a), whereas it was regarded as a split event by Cohen and Jones (2011) and Hu JG et al. (2014). Choi et al. (2019) reclassified the types of major SSWs based on the dominant components of wave 1 or wave 2 during the prewarming periods (before the central dates) and postwarming periods (after the central dates) as displacement-displacement type, displacement-split type, split-split type, and split-displacement type, respectively. However, the dominant wave amplitudes are not always consistent with the types of polar vortices. For example, the SSW that occurred on 26 February 1999 was suggested to be a split-type event by Charlton and Polvani (2007), Cohen and Jones (2011), and Rao J et al. (2019a) but a displacement-displacement event by Choi et al. (2019).

Recently, in 2018 and 2019, two major SSWs occurred continuously during the Arctic winters (e.g., Rao J et al., 2018, 2019b, 2020). The 2018 SSW, with a central date of 12 February 2018, was found to be related to the extremely cold winter over the European region (King et al., 2019; Lü ZZ et al., 2020) and ionospheric perturbations over the China sector (Liu GQ et al., 2019). The 2018 SSW was excited by the upward wavenumber 2 planetary waves, which were mainly related to the Ural and Alaska blockings (Rao J et al., 2018). The 2019 New Year SSW had a central date of 02 January 2019. Lee and Butler (2020) proposed that the 2019 SSW was triggered by a dominant wave 1 pattern without the wave 2 amplification seen in the 2018 SSW, whereas splitting polar vortices appeared again after the central date of the 2019 SSW. With the splitting vortices in the postwarming period, the 2019 SSW event was then regarded as a mixed-type (displacement-split) event (Rao J et al., 2019b). It is interesting to note that the splitting vortices could be observed in both wave 1-dominant and wave 2-dominant SSW events. The transitions of the polar vortices complicate the atmospheric variations during major SSW events. However, the stratospheric similarities and differences between conventional SSWs and atypical SSWs with transition vortices are not fully understood. The stratospheric conditions during different SSWs with transition vortices may also exhibit large discrepancies in the prewarming and postwarming periods.

In the present study, we compared the stratospheric evolution in the northern hemisphere at $10 \mathrm{hPa}$ during the major SSWs in 2018 and 2019, focusing on the temperatures, geopotential heights, and planetary waves separately in the prewarming and postwarming periods. Our primary goal was to present the differences between the two warming events and to investigate the similarities of SSWs with transition vortices. The data and methodology applied in this study are presented in Section 2. The results and discussion are given in Section 3. Conclusions are provided in Section 4.

\section{Data and Methodology}

Comparisons of the stratospheric evolution during the two major SSWs were made based on temperature and geopotential height data at $10 \mathrm{hPa}$ from the Modern-Era Retrospective analysis for Re- search and Applications, Version 2 (MERRA-2) reanalysis data set (Gelaro et al., 2017). Variations in the stratospheric temperatures were investigated to track the warming process. The evolution of the polar vortices was then presented via maps of the geopotential heights. Low values of the geopotential heights represent cyclones (polar vortices), whereas high values denote anticyclones. Note that the geopotential height data obtained from MERRA-2 and the geopotential data downloaded from the European Centre for Medium-Range Weather Forecasts Interim Reanalysis (ERA-Interim) revealed a consistent distribution of cyclones and anticyclones (Dee et al., 2011). The evolution of cyclones and anticyclones is discussed from 15 days before the central dates to 15 days afterward, whereas the results are shown every other day to avoid having an excessive number of figures. Throughout the 31-day period, the amplitudes of the stationary planetary waves (SPWs) with wavenumber 1 , wavenumber 2 , and wavenumber 3 were calculated according to the geopotential height data at $60^{\circ} \mathrm{N}$ and 10 $\mathrm{hPa}$ by the harmonic fitting analysis introduced by Lu $\mathrm{X}$ et al. (2018). The evolution of the North Atlantic Oscillation (NAO) indices was accessed from the National Centers for Environmental Prediction Climate Prediction Center (NCEP CPC) website (https://www.cpc.ncep.noaa.gov/). Note that the central date of each SSW in the present study was defined as the first date of the wind reversals at $60^{\circ} \mathrm{N}$ based on MERRA- 2 data. The onset date of each SSW was defined as the date with the maximum positive temperature difference between $90^{\circ} \mathrm{N}$ and $60^{\circ} \mathrm{N}$. Our definitions of the onset dates may differ slightly because of the definition by wind reversal, but they were used mainly to reveal the temperature enhancements in the polar region (Gong Y et al., 2019; Ma Z et al., 2020). In addition, definitions of the SSW type have varied in different studies. As mentioned above, different analytical methods can produce different types when classifying the same SSW event. In the present study, we analyzed the vortices based on the daily evolution of the maps of geopotential heights and discuss the transitions of the polar vortices. Our conclusion is not dependent on the classification of the vortex type.

\section{Results and Discussions}

\subsection{Prewarming Comparisons}

Because the transitions of polar vortices occur after the central dates, our comparisons between the two major SSWs were divided into two periods. One was in the prewarming period (before the central dates). The other was during the postwarming period (after the central dates). Figure panels $1 \mathrm{a}$ and $1 \mathrm{~b}$ present the daily mean temperatures in the northern hemisphere at 10 $\mathrm{hPa}$ in the 15 days prior to the central dates of the 2018 and 2019 SSWs, respectively. As shown in Figure 1a, lower temperatures were mainly in the western hemisphere from day -15 to day -5 in the 2018 SSW. Meanwhile, higher temperatures propagated continuously from the mid-latitudes around $60^{\circ} \mathrm{E}$ northeastward to high latitudes around $120^{\circ} \mathrm{E}$, but they were unable to occupy the entire Arctic region. On day -3 , in addition to the temperature-enhanced region around $120^{\circ} \mathrm{E}$, a warming area occurred at the midlatitudes around $60^{\circ} \mathrm{W}$. This new warming area expanded poleward into the high latitudes in the next 2 days and connected in the polar region with the other poleward temperature-enhanced 

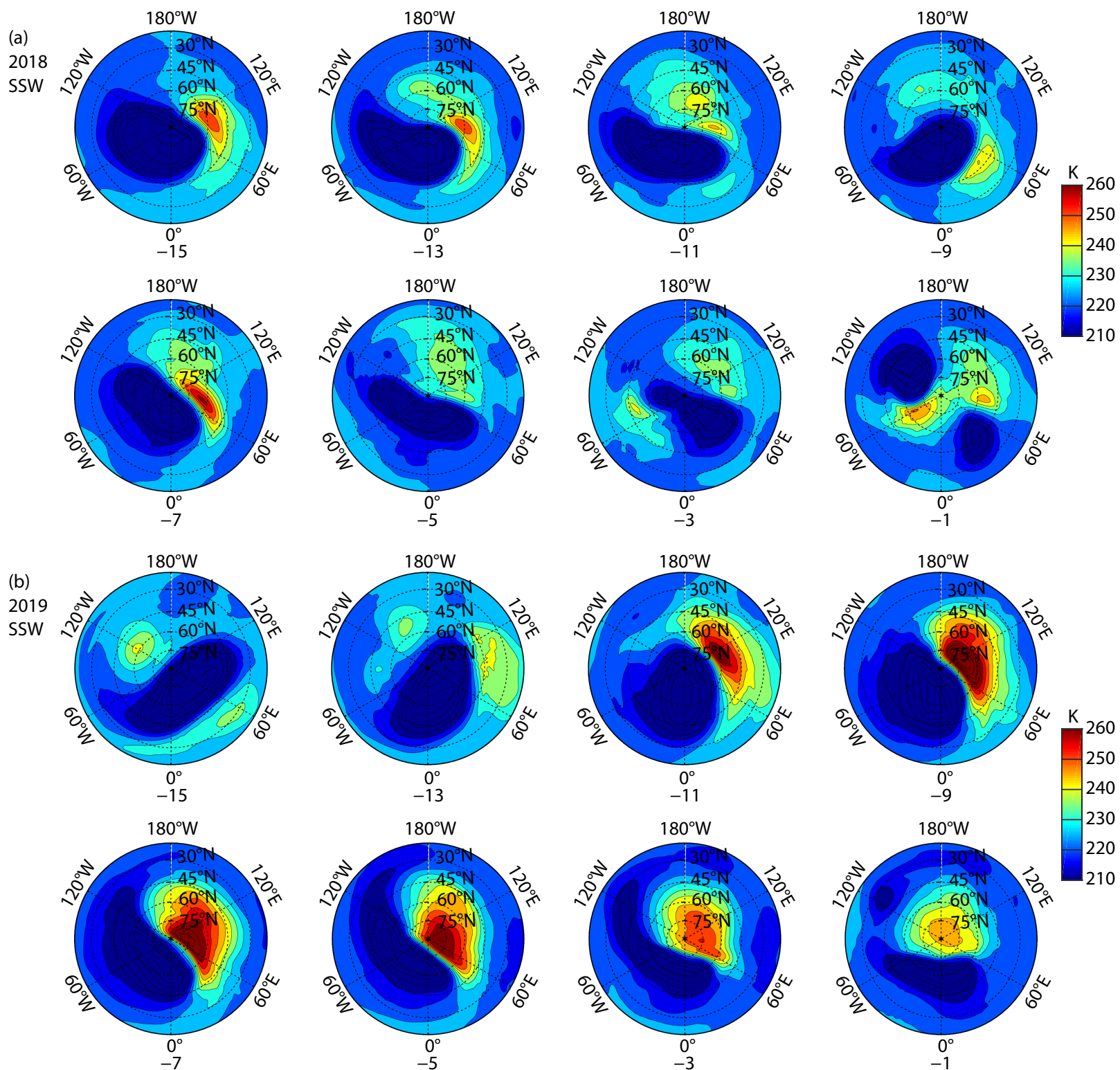

Figure 1. Daily mean temperatures in the northern hemisphere at $10 \mathrm{hPa}$ during the prewarming periods ( 15 days before the central dates) (a) in the 2018 SSW and (b) in the 2019 SSW. Synoptic maps are presented every other day with the negative number below, which is the number of days before the central date (day 0 ). The contour interval is $5 \mathrm{~K}$.

region around $120^{\circ} \mathrm{E}$ on day -1 . Compared with the $2018 \mathrm{SSW}$, the temperature evolution in the 2019 SSW (Figure $1 \mathrm{~b}$ ) revealed large differences in longitudinal distribution. The warming process appeared only in the eastern hemisphere and developed northeastward from the mid-latitudes around $60^{\circ} \mathrm{E}$ to the high latitudes around $120^{\circ} \mathrm{E}$. However, the temperature-enhanced route in the western hemisphere was absent in the prewarming period of the 2019 SSW. In addition, the warming air in the polar region occurred much earlier in the 2019 SSW (around day -5), and the temperature in the polar region seemed to decrease from day -5 to day -1 . In fact, the zonal mean temperature difference between $90^{\circ} \mathrm{N}$ and $60^{\circ} \mathrm{N}$ reached the maximum on day $-5(28$ December 2018), which can be considered the onset date of the 2019 SSW (Ma Z et al., 2020). The occurrence and duration of the poleward temperature-enhanced process in the prewarming peri- od were not specifically related to the time of the central date but may have been associated with the onset dates of major SSWs. Figure 1 indicates that the poleward temperature-enhanced process may have occurred earlier (before the onset date) than the wind reversal at $60^{\circ} \mathrm{N}$ (central date). Our results also revealed that the temperature-enhanced regions may have had different longitudes during the different SSW events.

The evolution of geopotential heights in the prewarming periods of the 2018 and 2019 SSWs are presented in Figure 2. Following previous studies (e.g., Rao J et al., 2018, 2019b; Lee and Butler, 2020; Lü ZZ et al., 2020), the region with a high-value geopotential height suggests an anticyclone, whereas the area with a lowvalue geopotential height indicates a cyclone (polar vortex). As shown in Figure $2 \mathrm{a}$, the polar vortices did not have significant displacement features from day -15 to day -7 . The anticyclone 

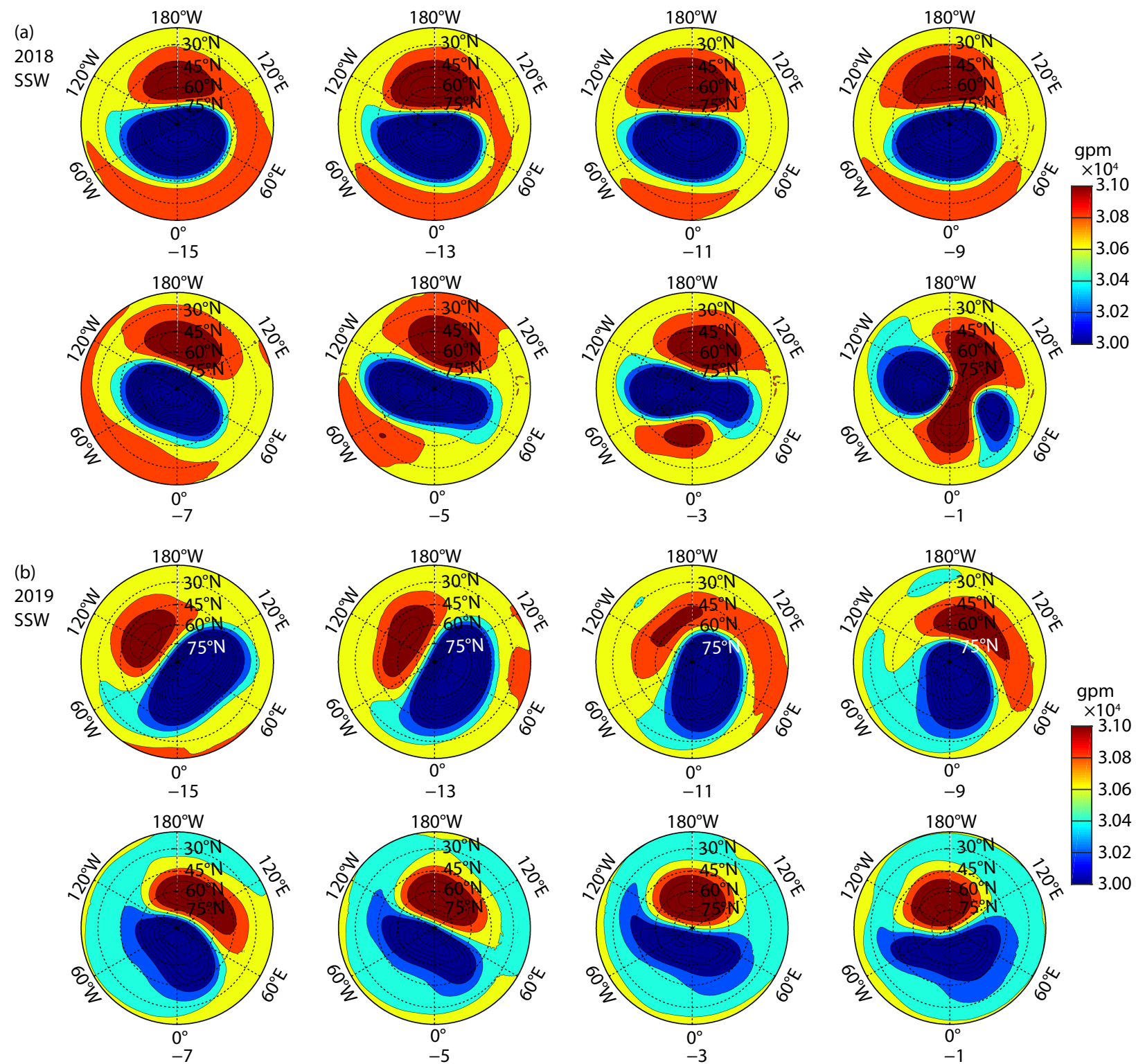

Figure 2. Same as Figure 1 but for the daily mean geopotential heights. The contour interval is $200 \mathrm{gpm}$.

around the $180^{\circ}$ meridian, known as the Aleutian High (Harvey and Hitchman, 1996), was located stably over the northern Pacific Ocean. From day -5 , the anticyclone over the Atlantic Ocean became stronger and moved poleward together with the Aleutian High. These two poleward anticyclones began to push the polar vortex after day -3 and split it into two daughter vortices on day -1 . Thus, the 2018 SSW was classified as a split type in previous studies on the basis of these vortex distributions (e.g., Rao J et al., 2018, 2019a; Harada et al., 2019; Lee et al., 2019). Unlike the longlasting split vortices that occurred before the onset of the wellknown 2009 SSW event (e.g., Ayarzagüena et al., 2011), the vortex in the prewarming period of the 2018 SSW split suddenly because of the sharply enhanced anticyclone over the Atlantic region on day -3 . The abruptly enhanced anticyclone may also have made the 2018 SSW event less likely to be forecast well by models (e.g., Rao J et al., 2018; Lee et al., 2019). The evolution of geopotential heights in the prewarming period of the 2019 SSW revealed only a displaced polar vortex with the Aleutian High, as shown in Figure
$2 b$, which is similar to the results shown by Rao J et al. (2019b). The polar vortex first tilted eastward to the Eurasian region and then extended westward to the Atlantic region after day -11 . This process may be related to the attenuation of the high-latitude zonal winds at the beginning of the SSW event. It is interesting that the polar vortex weakened and seemed to become elongated from Europe to North America after day -7 . On day -5 and day -3 , the polar vortex was centrally located over the Atlantic region from $0^{\circ}$ westward to $60^{\circ} \mathrm{W}$. Nevertheless, the evolution of the polar vortex did not show any splitting distribution in the prewarming period of the 2019 SSW. Therefore, the 2019 SSW exhibited a displacement type based on the evolution of geopotential heights in the prewarming period (e.g., Rao J et al., 2019b).

As shown in Figures 1 and 2, note that the temperature enhancement occurred only around $120^{\circ} \mathrm{E}$ before the $2019 \mathrm{SSW}$ with a displacement vortex but that it increased around both $120^{\circ} \mathrm{E}$ and $60^{\circ} \mathrm{W}$ before the $2018 \mathrm{SSW}$ with splitting vortices. These longitud- 
inal dependencies may have been related to the evolution of anticyclones in the prewarming periods. For instance, the distribution of the air temperature was zonally symmetrical, based on the split vortices in the 2018 SSW, which may have been caused by the two-peak anticyclonic structure. The Aleutian High and the EuroAtlantic anticyclone could have forced the northward winds on the western side and promoted the poleward propagation of warming air (Kozubek et al., 2015). In general, the Aleutian High persists in the stratosphere during most Arctic winters (e.g. Lastovicka et al., 2018). The Aleutian High continuously transfers warming air to high latitudes during winters, for example, from day -15 to day -7 in the 2018 SSW. Thus, the poleward temperature-enhanced phenomenon can commonly be seen around $120^{\circ} \mathrm{E}$, especially before major SSW events. However, the anticyclone sometimes arises unexpectedly in a short time over the EuroAtlantic region, leading to a poleward temperature enhancement around $60^{\circ} \mathrm{W}$. The evolution in the prewarming period of the 2018
SSW further indicates that the poleward temperature-enhanced processes occurring around both $120^{\circ} \mathrm{E}$ and $60^{\circ} \mathrm{W}$ finally connect over the polar region. This evolution is conducive to classifying the 2018 SSW as a split-type SSW event in the prewarming periods (e.g., Rao J et al., 2018, 2020). The frequency with which an anticyclone occurs over the Euro-Atlantic region is not high during Arctic winters (e.g., Lastovicka et al., 2018), which is also consistent with the lower frequency of split-type events in the prewarming periods (e.g., Choi et al., 2019). Comparisons of the 2018 and 2019 SSWs in the prewarming periods revealed that the longitudinal dependencies of the poleward temperature-enhanced regions were closely accompanied by anticyclones and polar vortices.

\subsection{Postwarming Comparisons}

Figure 3 shows the evolution of temperature in the postwarming periods in the 2018 and 2019 SSWs. The warming air was concen-
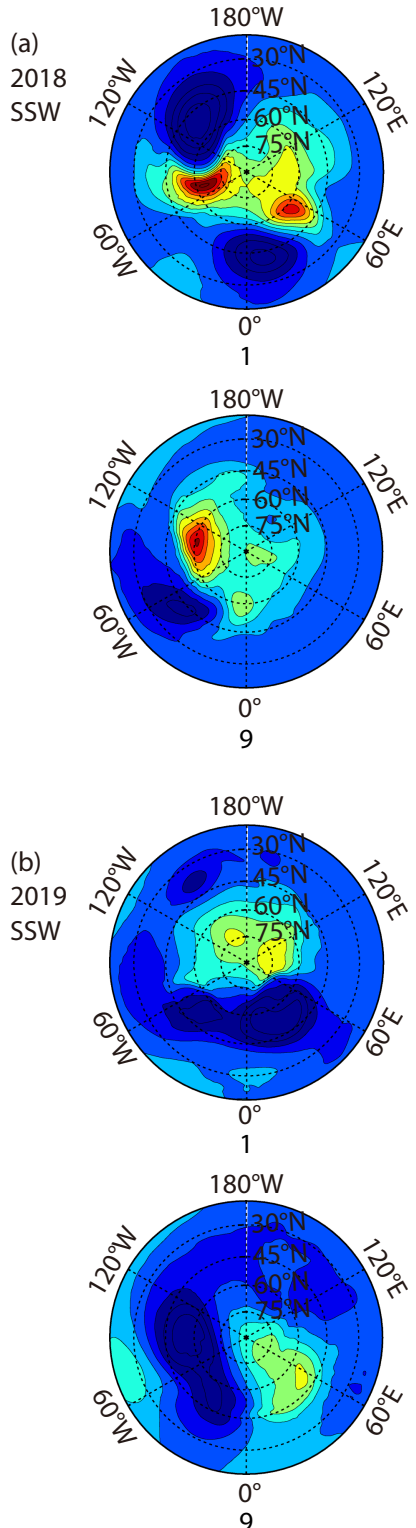

9
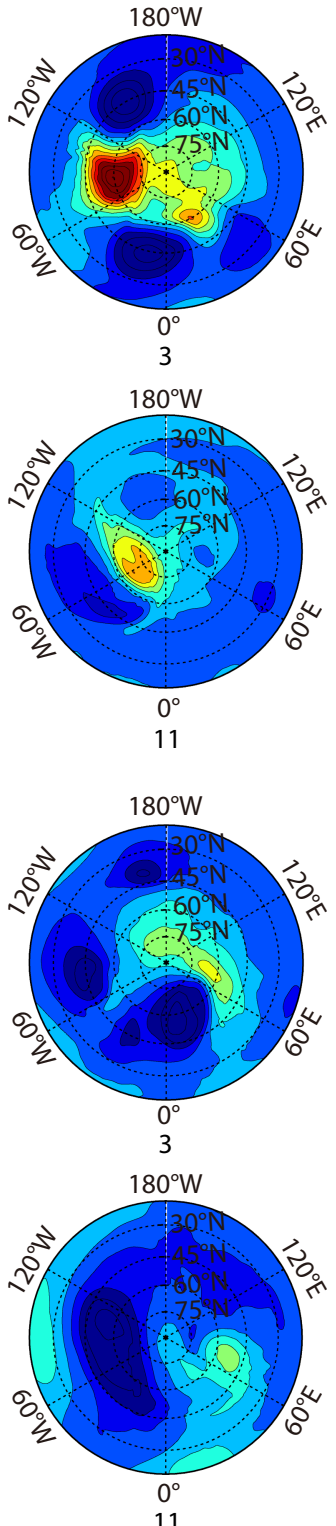

11
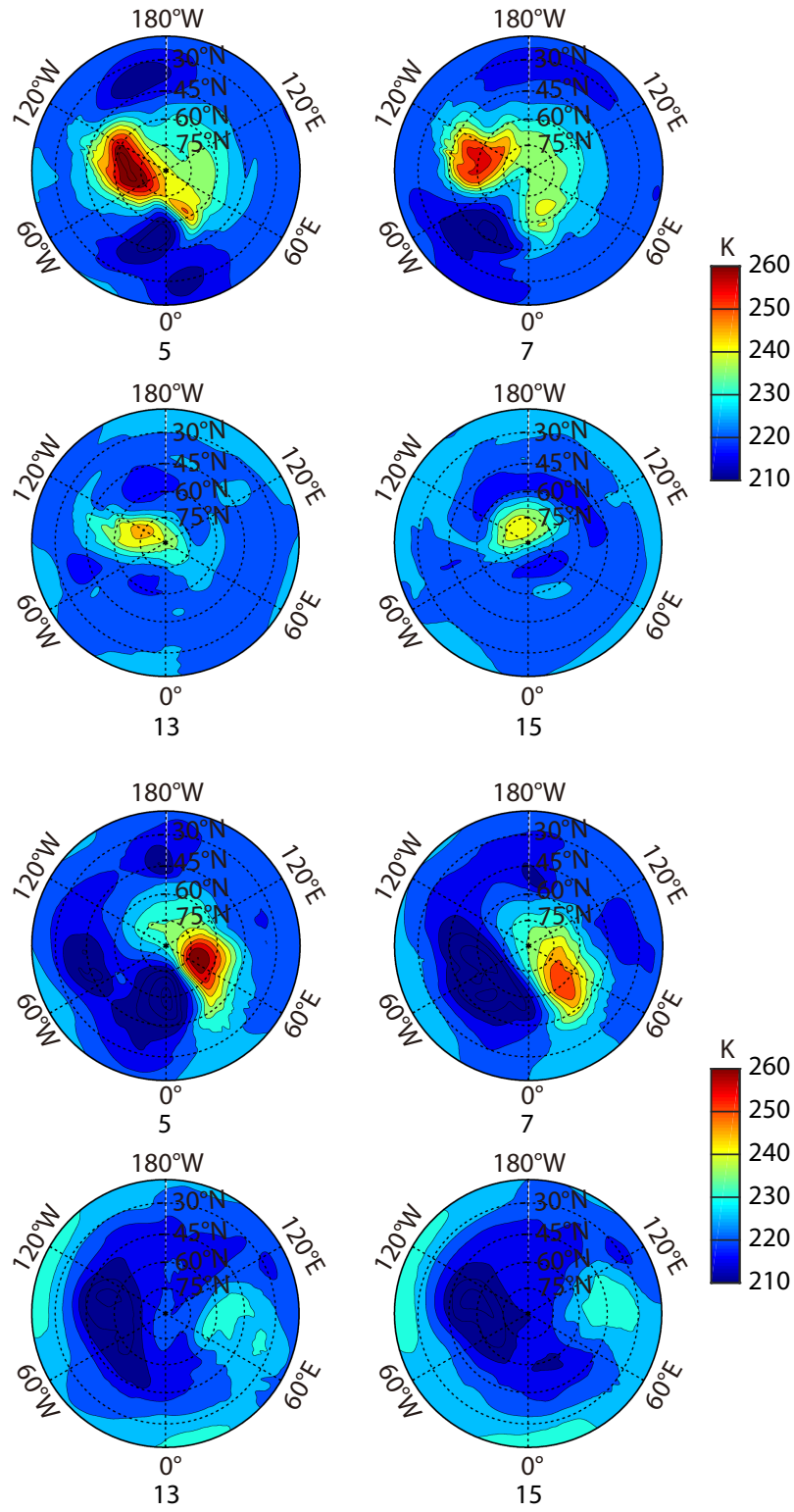

Figure 3. Same as Figure 1 but for the postwarming periods. 
trated over the North American region in the postwarming period of the 2018 SSW. This secondary enhancement had a higher maximum value (more than $260 \mathrm{~K}$ ) than in the prewarming period. The other enhancement was a gradual weakening over the European region from day 1 to day 9 and its disappearance after day 11 . In the postwarming period of the 2019 SSW, a secondary enhancement of air temperature was also observed at high latitudes while the SSW was located over the Eurasian region. Note that we observed a secondary enhancement at high latitudes in both postwarming periods of the two major SSWs. These secondary enhancements extended the warming time in the stratospheric polar region after the onset dates of the major SSWs. As shown in Figure 3a, the warming air over the Eurasian region moved toward the North American region via the polar region from day 1 to day 5 , which may have been responsible for the secondary en- hancement that was concentrated over the North American sector in the postwarming period of the 2018 SSW. However, the secondary enhancement in the postwarming period of the 2019 SSW was likely due to the warming air shifting westward from the Pacific Ocean to the Eurasian region.

In addition to propagating warming air in the stratosphere, the polar vortices shown in Figure 4 also indicate significant transitions in the postwarming periods in both the 2018 and 2019 SSWs. The polar vortices were not symmetrical, having a $180^{\circ}$ longitudinal difference over North America and Asia after the central date of the 2018 SSW. The Asian vortex became weaker and propagated westward to the Atlantic region from day 1 to day 3 . From day 5 to day 7, the weakening vortex combined with the North American vortex, which ended the previous splitting distributions. The recombined vortex over the North American region
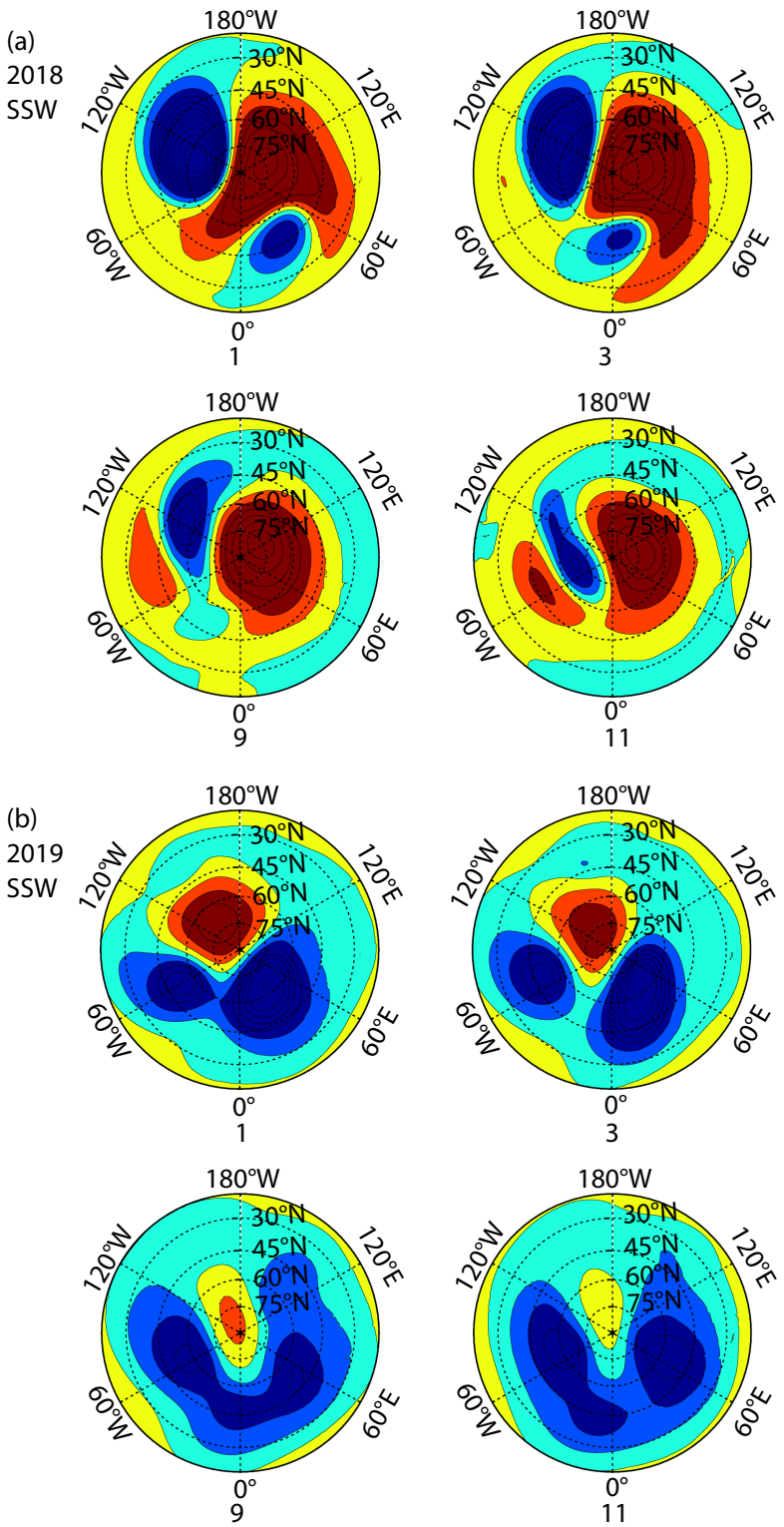
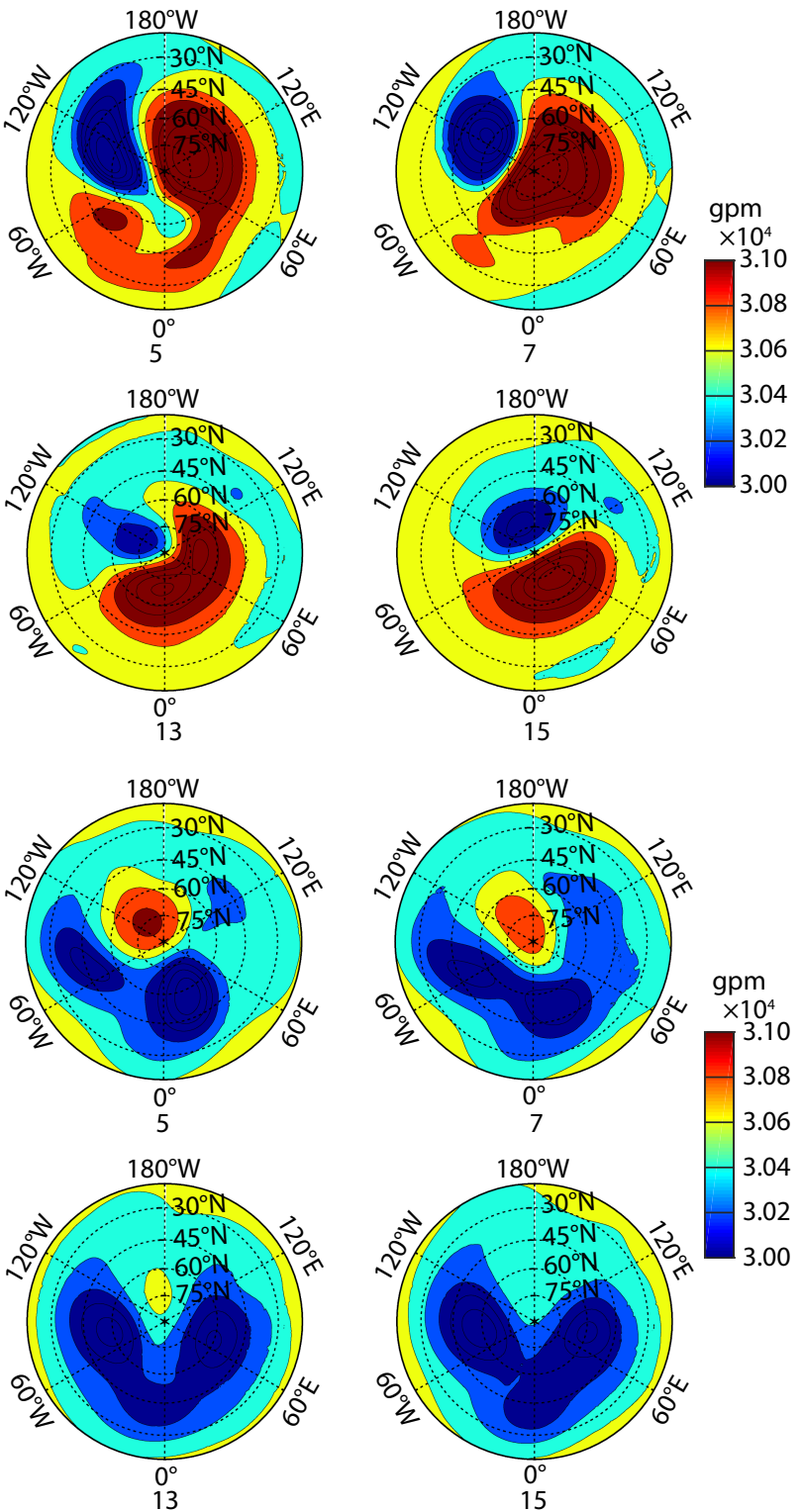

Figure 4. Daily mean geopotential heights in the northern hemisphere at $10 \mathrm{hPa}$ during the 15 days of the postwarming period (a) in the 2018 SSW and (b) in the 2019 SSW. Synoptic maps are presented every other day with the positive number below, which is the number of days after the central date (day 0). The contour interval is $200 \mathrm{gpm}$. 
and the major anticyclone over the Eurasian region then propagated westward together from day 9 to day 15 , and it developed a displaced vortex in the postwarming period of the 2018 SSW. This was the first time that the recombination process in the postwarming period of a split-type SSW event had been observed, and it was obviously different from the multiple vortices that formed after the 2009 split-type SSW (e.g., Manney et al., 2009). Figure 5a presents the evolution of the polar vortices in the postwarming periods of the 2009 SSW. Comparisons between Figure 4a and Figure 5a indicate that the vortex recovery process of the 2018 SSW was very different from that during the 2009 SSW. The splitting vortices in the postwarming period of the 2009 SSW were separated over the North American region and the Eurasian region from day 1 to day 3 . The vortices then moved a little westward after day 5. The Eurasian vortex was further split on day 7. Nevertheless, the splitting vortices in the postwarming period of the 2009 SSW were gradually weakened without any recombina- tion process like that shown in the postwarming period of the 2018 SSW. The recombined vortex in the 2018 SSW strengthened the cyclone over the North American region, whereas the cyclone controlled the Eurasian region for a longer time after the central date of the 2009 SSW.

In the postwarming period of the 2019 SSW, we also observed a transition of the polar vortex. As shown in Figure $4 b$, the polar vortex began to split into two daughter vortices after the central date and were separated on both the western and eastern sides of the Atlantic region. Rao J et al. (2019b, 2020) suggested that the difference in longitude between the two vortices was less than $120^{\circ}$, which was due to the enhancement of wave 3 . Note that only one anticyclone (the Aleutian High) occurred in the postwarming period of the 2019 SSW. However, the polar vortex still split without the anticyclone over the Euro-Atlantic region, as shown in Figure 2a. The splitting vortices gradually controlled the North American region and the Eurasian region from day 9 to day 15 , al-
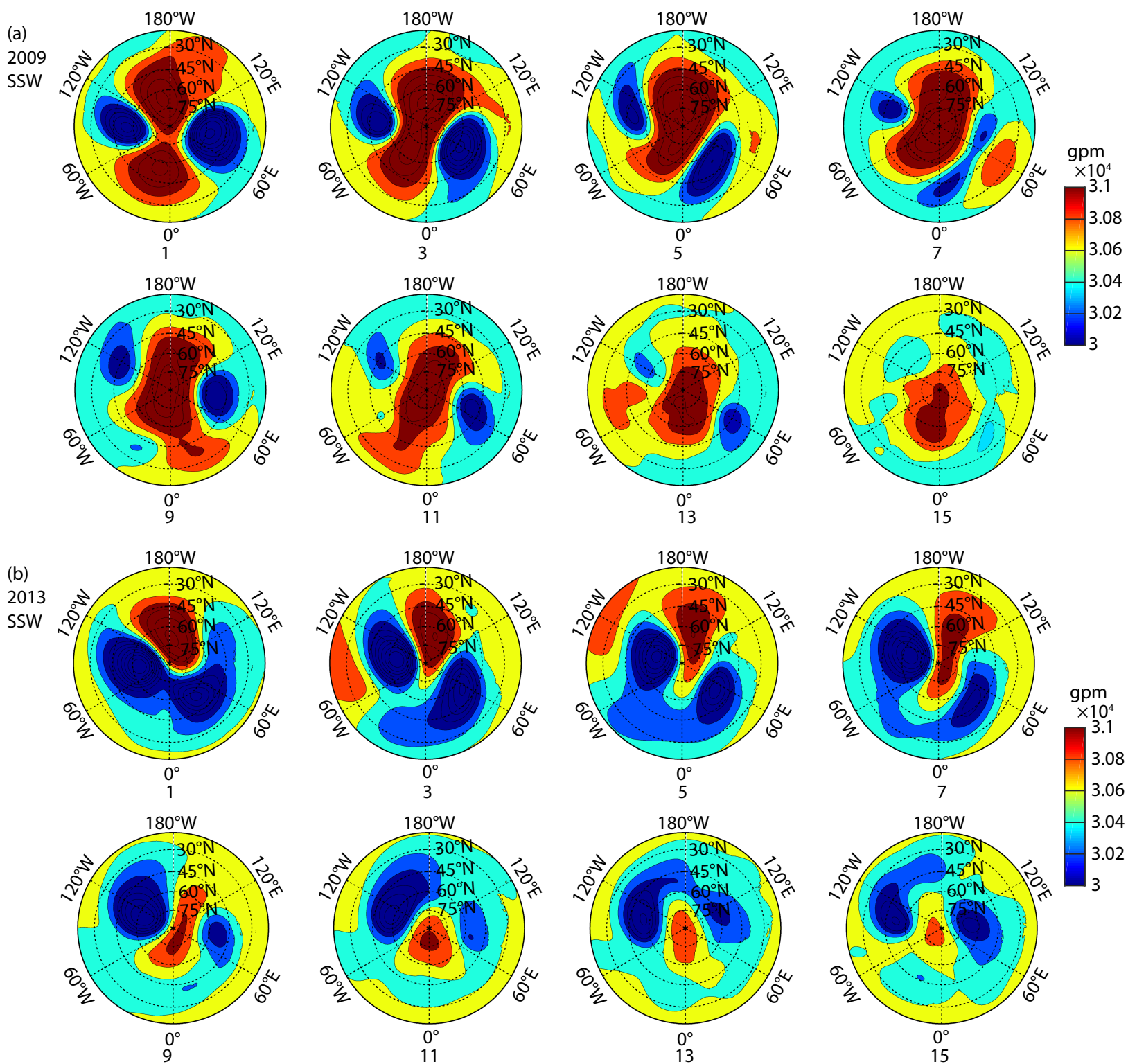

15

Figure 5. Same as Figure 4 but for (a) the 2009 SSW and (b) the 2013 SSW. 
though the anticyclone was weakening during the same period. This transition of the vortices indicates that the 2019 SSW can be classified as a displacement-split-type event. The evolution of the vortices in the 2019 SSW was very similar to the vortices in the 2013 SSW (as shown in Figure 5b), which also had splitting vortices with only one anticyclone in the postwarming period. The transitions of the polar vortices in the postwarming periods of the 2018 and 2019 SSWs are worth noting because the evolution of the polar vortices during SSWs can further influence the surface climate (e.g., Mitchell et al., 2013; Liu Y and Zhang YL, 2014; Nath et al., 2016; Rao J et al., 2020). However, what causes these transitions in the polar vortices or what the similarity is between these transition SSWs is not known.

In general, planetary wave activities are considered a significant driver of the atmospheric dynamics during SSWs (e.g., Azeem et al., 2005; Goncharenko et al., 2012; Shi CH et al., 2017; Cao C et al., 2019). The vortex types during SSWs are believed to be connected to the dominant planetary waves in the prewarming periods; that is, wave 1 plays a primary role in displacement events, whereas wave 2 dominates in split events (e.g., Harada and Hirooka, 2017; Liu SM et al., 2019). To further understand the wave evolution during the 2018 and 2019 SSWs, the day-to-day amplitudes of the SPWs with wavenumber 1 (SPW1), wavenumber 2 (SPW2), and wavenumber 3 (SPW3) were calculated at pressure levels of $10 \mathrm{hPa}$ based on the geopotential height at $60^{\circ} \mathrm{N}$. Figure 6 illustrates the evolution of the SPW1, SPW2, and SPW3 from day -15 to day 15. In the prewarming periods of the 2018 SSW, the amplitudes of wave 1 decreased by about $1 \mathrm{~km}$ and the amplitudes of wave 2 increased during the descending periods of wave 1 . Wave 2 was larger than wave 1 from day -5 to day -1 in the 2018 SSW, which dominated closer to the central date and was expected to be consistent with the typical split-type vortices. Wave 1 decreased by about $0.6 \mathrm{~km}$ in the prewarming period of the 2019 SSW and dominated from day -10 to day 0 with a relatively stable amplitude of $0.9 \mathrm{~km}$. Wave 2 had a peak amplitude of only about $0.4 \mathrm{~km}$ around day -10 and decreased to nearly zero on day 0 . Dominant wave 1 and decreased wave 2 were related to the displacement vortex in the prewarming periods of the 2019 SSW, as shown in Figure $2 \mathrm{~b}$. Thus, the status of the vortices could be explained by the evolution of the dominant waves in the prewarming periods in both SSW events. In the postwarming period of the 2018 SSW, wave 2 decreased sharply, whereas wave 1 again dominated from day 0 . The recombination of the vortices in the 2018 SSW was very likely due to this transition of the wave amplitudes. According to Choi et al. (2019), the 2018 SSW can be classified as a split-displacement-type SSW, similar to the 2007 SSW, because wave 1 dominated wave 2 during the entire postwarming period after wave 2 dominated during the prewarming period. However, the splitting vortices in the 2019 SSW were not consistent with the most prominent SPWs. Rao J et al. (2019b) attributed the splitting vortices in the 2019 SSW to enhancements of the tropospheric wave 3. The SPWs also indicated an enhancement of the stratospheric wave 3 around day 2 , and three vortices were observed on day 5 , as shown in Figure 4b. Nevertheless, wave 2 had the least influence on the splitting vortices around the central date of the 2019 SSW. As shown in Figure 6 (right), the amplitudes of wave 2 were smaller than $0.2 \mathrm{~km}$ until day 8 , although the dominant wave 1 kept weakening during the postwarming period. Lee and Butler (2020) also proposed that the 2019 SSW had a splitting vortex without the wave 2 amplification.

According to the postwarming vortices shown in Figure 4, the recombination and splitting vortices were all observed over the Atlantic region $\left(0^{\circ}-60^{\circ} \mathrm{W}\right)$. Choi et al. (2020) suggested that the negative NAO phase pattern may have contributed to the enhanced wave 2 component and favored displacement-split-type SSW events. However, the amplitudes of wave 2 were extremely low at the central date of the 2019 SSW, when the displacement-split vortex occurred. To further check the relationship between the negative NAO and the splitting vortices, we examined the evolution of the NAO index (Figure 7) during four recent major SSWs, namely, the 2019 SSW, the 2018 SSW, the 2013 SSW (central date on 06 January 2013), and the 2009 SSW (central date on 24 January 2009), respectively. The 2009 SSW (e.g., Harada et al., 2010; Gong Y et al., 2019; Rao J et al., 2019a) was a typical split-type event but without the recombination vortices in the postwarming period, as shown in Figure 5a. The 2013 SSW (e.g., Coy and
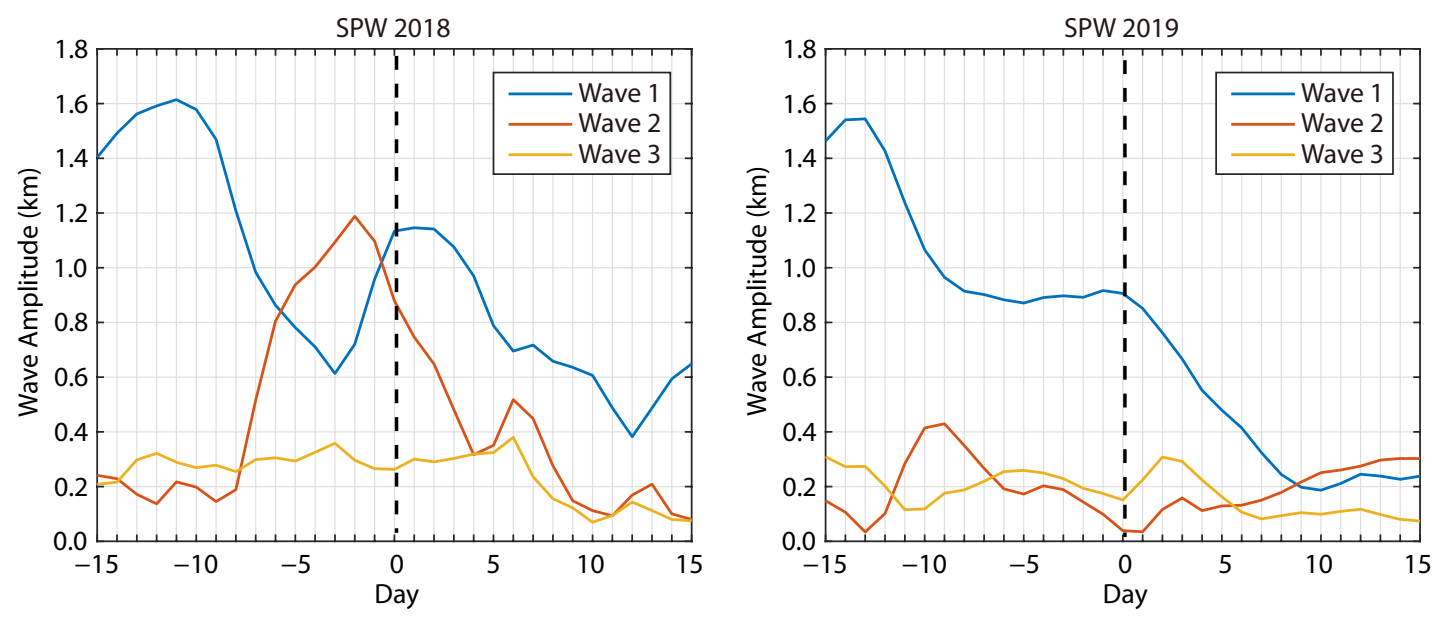

Figure 6. Amplitudes of the stationary planetary waves (SPWs) during the 2018 SSW (left) and the 2019 SSW (right). Wave 1, wave 2, and wave 3 are represented by the blue, red, and yellow curves, respectively. 


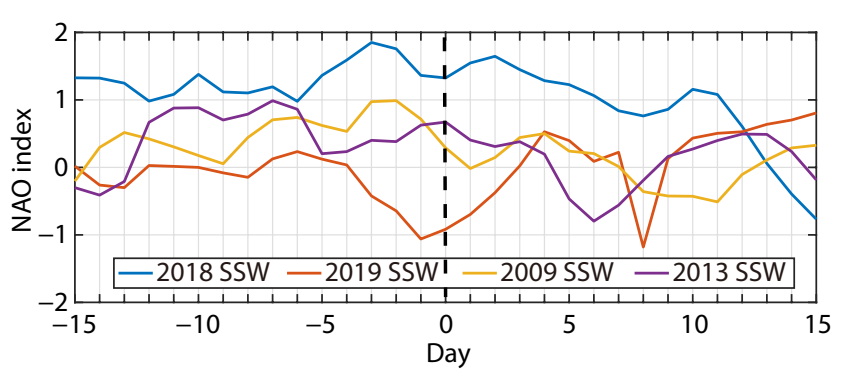

Figure 7. Evolution of the North Atlantic Oscillation (NAO) indices during the 2018 SSW (blue), the 2019 SSW (red), the 2009 SSW (yellow), and the 2013 SSW (purple). The black dashed line on day 0 denotes the central dates of these major SSWs.

Pawson, 2015; Ma Z et al., 2017; Gong Y et al., 2018b, 2019) was a displacement-split-type event with the splitting vortices over the Atlantic region just after the central date, as shown in Figure 5b, which is very similar to the 2019 SSW. Comparison of the NAO indices during these four major SSWs revealed a weak correlation between the negative NAO phases and the transitions of the vortices. For instance, the 2013 SSW had a positive-phase NAO index from day -12 to day 4 , whereas a negative-phase NAO index appeared around the central date of the 2019 SSW. The NAO indices were both in a positive phase before day 5 in the 2018 SSW and the 2009 SSW, and splitting vortices were observed in both events. Thus, the negative phase of the NAO index was not responsible for the splitting vortices in the 2018, 2009, and 2013 SSWs, which indicates that the transitions of the polar vortices in the postwarming period may be further related to other factors over the Atlantic sector.

In addition to the enhanced planetary waves and the negative phase of the NAO, the transitions of the polar vortices seem to be influenced mainly by the development of anticyclones over the polar region. In the postwarming period of the 2018 SSW, the recombination vortices may have been due to a weakening of the Euro-Atlantic peak, which moved into the Pacific region through the polar region, as shown in Figure 4a, leaving uncontrolled areas over the Atlantic region. This evolution may have allowed the weak vortex around $60^{\circ} \mathrm{E}$ to recombine with the strong western vortex under the westward wind, forcing in the postwarming period of this major event. The splitting vortices in the postwarming period of the 2019 SSW may have been related to the highvalue geopotential height moving in the opposite direction, which was developing from the Aleutian High toward the Atlantic region via the polar region. This process may have cut the polar vortex into two daughter vortices. Harvey et al. (2002) reported a splitting vortex in 1999 that was led by a merger of stratospheric anticyclones, indicating that variations in the anticyclones could influence the distribution of the polar vortices. Coy and Pawson (2015) found splitting vortices similar to the 2019 SSW over the Atlantic region after the central date of the 2013 SSW. In their discussion, they proposed that the major wave forcing was found only in the Pacific sector and was not obvious in the Atlantic sector in the postwarming period of the 2013 SSW. As shown in Figure $5 b$, the anticyclone revealed a clear propagation in the postwarming period of the 2013 SSW, which moved from the Pacific sector to the Atlantic sector and segregated the splitting vor- tices into the North American region and the Eurasian region. The single direction of the anticyclone in the 2019 SSW also developed from the Pacific sector toward the Atlantic sector. It remains to be studied whether the Pacific wave forcing is responsible for the shifts of the anticyclone during all the displacement-split events. Nevertheless, the transition vortices observed in the 2013, 2018, and 2019 SSWs may all have been related to the evolution of anticyclones between the Pacific region and the Atlantic region, crossing the polar region. It is still unclear what is controlling this evolution. Statistical analysis is needed to further study the triggering mechanism of the SSWs with transition vortices.

\section{Conclusions}

Stratospheric evolution of the temperature and geopotential height during two major SSW events that occurred in February 2018 and January 2019 were investigated based on MERRA-2 reanalysis data. In the prewarming period, poleward enhancement of the stratospheric temperature from the mid-latitudes to the polar region had a clear longitudinal dependence. The temperature enhancement occurred around $120^{\circ} \mathrm{E}$ before the 2019 SSW with a displacement vortex, whereas it appeared at both $60^{\circ} \mathrm{W}$ and $120^{\circ} \mathrm{E}$ before the $2018 \mathrm{SSW}$ with a splitting vortex. In the postwarming period, an unexpected recombination of the polar vortex was observed in the 2018 SSW, whereas splitting vortices were found in the 2019 SSW. This was the first time a recombination vortex had been reported in the postwarming period of a split-type SSW. A secondary enhancement of wave 1 and a sudden decrease of wave 2 may have been responsible for this recombination. However, the evolution of wave 1 and wave 2 cannot fully explain the splitting vortices in the postwarming period of the 2019 SSW. The enhancement of tropospheric wave 3 may have been responsible for the splitting vortices in the 2019 SSW (e.g., Rao J et al., 2019b). It is interesting that we observed all the transitions of the polar vortices over the Atlantic region, whereas negative phases of the NAO indices, as suggested by Choi et al. (2020), may not always be suitable to explain the splitting vortices. The stratospheric evolution of the geopotential heights indicates that the recombination vortex in the 2018 SSW may have been due to the Euro-Atlantic anticyclone moving into the Pacific region through the polar region, whereas the splitting vortices in the 2019 SSW may have been related to the anticyclones moving from the Aleutian High toward the Atlantic region via the polar region. Our results suggest that the Atlantic region may be a crucial region during the SSWs with transition vortices. Hence, future studies are needed to further investigate the mechanisms of the transition of polar vortices in the Atlantic region.

\section{Acknowledgments}

The MERRA2 data can be obtained from NASA (https://disc.gsfc. nasa.gov/datasets?page=1\&project=MERRA-2). This study was supported by the National Natural Science Foundation of China (grants 41574142 and 41531070), the Specialized Research Fund for State Key Laboratories, and the National Science Foundation (grant AGS-1744033). 


\section{References}

Albers, J. R., and Birner, T. (2014). Vortex preconditioning due to planetary and gravity waves prior to sudden stratospheric warmings. J. Atmos. Sci., 71(11), 4028-4054. https://doi.org/10.1175/JAS-D-14-0026.1

Andrews, D. G., Holton, J. R., and Leovy, C. B. (1987). Middle Atmosphere Dynamics. San Diego, Calif.: Academic Press.

Ayarzagüena, B., Langematz, U., and Serrano, E. (2011). Tropospheric forcing of the stratosphere: A comparative study of the two different major stratospheric warmings in 2009 and 2010. J. Geophys. Res. Atmos., 116(D18), D18114. https://doi.org/10.1029/2010JD015023

Azeem, S. M. I., Talaat, E. R., Sivjee, G. G., Liu, H. L., and Roble, R. G. (2005). Observational study of the 4-day wave in the mesosphere preceding the sudden stratospheric warming events during 1995 and 2002. Geophys. Res. Lett., 32(15), L15804. https://doi.org/10.1029/2005GL023393

Butler, A. H., Sjoberg, J. P., Seidel, D. J., and Rosenlof, K. H. (2017). A sudden stratospheric warming compendium. Earth Syst. Sci. Data, 9(1), 63-76. https://doi.org/10.5194/essd-9-63-2017

Cao, C., Chen, Y. H., Rao, J., Liu, S. M., Li, S. Y., Ma, M. H., and Wang, Y. B. (2019). Statistical characteristics of major sudden stratospheric warming events in CESM1-WACCM: A comparison with the JRA55 and NCEP/NCAR reanalyses. Atmosphere, 10(9), 519. https://doi.org/10.3390/atmos10090519

Charlton, A. J., and Polvani, L. M. (2007). A new look at stratospheric sudden warmings. Part I: Climatology and modeling benchmarks. J. Climate, 20(3), 449-469. https://doi.org/10.1175/JCLI3996.1

Choi, H., Kim, B. M., and Choi, W. (2019). Type classification of sudden stratospheric warming based on pre- and postwarming periods. J. Climate, 32(8), 2349-2367. https://doi.org/10.1175/JCLI-D-18-0223.1

Choi, H., Choi, W., Kim, S. J., and Kim, B. M. (2020). Dependence of sudden stratospheric warming type-transition on preceding North Atlantic Oscillation conditions. Atmos. Sci. Lett., 21(3), e953. https://doi.org/10.1002/asl.953

Cohen, J., and Jones, J. (2011). Tropospheric precursors and stratospheric warmings. J. Climate, 24(24), 6562-6572. https://doi.org/10.1175/2011JCLI4160.1

Coy, L., and Pawson, S. (2015). The major stratospheric sudden warming of January 2013: Analyses and Forecasts in the GEOS-5 Data Assimilation System. Mon. Wea. Rev., 143(2), 491-510. https://doi.org/10.1175/MWR-D14-00023.1

Dee, D. P., Uppala, S. M., Simmons, A. J., Berrisford, P., Poli, P., Kobayashi, S., Andrae, U., Balmaseda, M. A., Balsamo, G., ... Vitart, F. (2011). The ERAInterim reanalysis: configuration and performance of the data assimilation system. Quart. J. Roy. Meteor. Soc., 137(656), 553-597. https://doi.org/10.1002/qj.828

Gelaro, R., McCarty, W., Suárez, M. J., Todling, R., Molod, A., Takacs, L., Randles, C. A., Darmenov, A., Bosilovich, M. G., ... Zhao, B. (2017). The modern-era retrospective analysis for research and applications, Version 2 (MERRA-2). J. Climate, 30(14), 5419-5454. https://doi.org/10.1175/JCLI-D-16-0758.1

Goncharenko, L. P., Coster, A. J., Plumb, R. A., and Domeisen, D. I. V. (2012). The potential role of stratospheric ozone in the stratosphere-ionosphere coupling during stratospheric warmings. Geophys. Res. Lett., 39(8), L08101. https://doi.org/10.1029/2012GL051261

Gong, Y., Zhou, Q. H., and Zhang, S. D. (2013). Atmospheric tides in the lowlatitude $E$ and $F$ regions and their responses to a sudden stratospheric warming event in January 2010. J. Geophys. Res. Space Phys., 118(12), 7913-7927. https://doi.org/10.1002/2013JA019248

Gong, Y., Zhou, Q. H., Zhang, S. D., Aponte, N., and Sulzer, M. (2016). An incoherent scatter radar study of the midnight temperature maximum that occurred at Arecibo during a sudden stratospheric warming event in January 2010. J. Geophys. Res. Space Phys., 121(6), 5571-5578. https://doi.org/10.1002/2016JA022439

Gong, Y., Ma, Z., Lv, X. D., Zhang, S. D., Zhou, Q. H., Aponte, N., and Sulzer, M. (2018a). A study on the quarterdiurnal tide in the thermosphere at Arecibo during the February 2016 sudden stratospheric warming event. Geophys. Res. Lett., 45(23), 13142-13149. https://doi.org/10.1029/2018GL080422

Gong, Y., Li, C., Ma, Z., Zhang, S. D., Zhou, Q. H., Huang, C. M., Huang, K. M., Li, G.
Z., and Ning, B. Q. (2018b). Study of the quasi-5-day wave in the MLT region by a meteor radar chain. J. Geophys. Res. Atmos., 123(17), 9474-9487. https://doi.org/10.1029/2018JD029355

Gong, Y., Wang, H. L., Ma, Z., Zhang, S. D., Zhou, Q. H., Huang, C. M., and Huang, K. M. (2019). A statistical analysis of the propagating quasi 16-day waves at high latitudes and their response to sudden stratospheric warmings from 2005 to 2018. J. Geophys. Res. Atmos., 124(23), 12617-12630. https://doi.org/10.1029/2019JD031482

Harada, Y., Goto, A., Hasegawa, H., Fujikawa, N., Naoe, H., and Hirooka, T. (2010) A major stratospheric sudden warming event in January 2009. J. Atmos. Sci. 67(6), 2052-2069. https://doi.org/10.1175/2009JAS3320.1

Harada, Y., and Hirooka, T. (2017). Extraordinary features of the planetary wave propagation during the boreal winter 2013/2014 and the zonal wave number two predominance. J. Geophys. Res. Atmos., 122(21), 11374-11387. https://doi.org/10.1002/2017JD027053

Harada, Y., Sato, K., Kinoshita, T., Yasui, R., Hirooka, T., and Naoe, H. (2019). Diagnostics of a WN2-type major sudden stratospheric warming event in February 2018 using a new three-dimensional wave activity flux. J. Geophys. Res. Atmos., 124(12), 6120-6142. https://doi.org/10.1029/2018JD030162

Harvey, V. L., and Hitchman, M. H. (1996). A climatology of the Aleutian High. J. Atmos. Sci., 53(14), 2088-2102. https://doi.org/10.1175/15200469(1996)053<2088:ACOTAH>2.0.CO;2

Harvey, V. L., Pierce, R. B., Fairlie, T. D., and Hitchman, M. H. (2002). A climatology of stratospheric polar vortices and anticyclones. J. Geophys. Res. Atmos., 107(D20), ACL 10-1-ACL 10-22. https://doi.org/10.1029/2001JD001471

Hu, J. G., Ren, R. C., and Xu, H. M. (2014). Occurrence of winter stratospheric sudden warming events and the seasonal timing of spring stratospheric final warming. J. Atmos. Sci., 71(7), 2319-2334. https://doi.org/10.1175/JASD-13-0349.1

Karpechko, A. Y., Charlton-Perez, A., Balmaseda, M., Tyrrell, N., \&Vitart, F. (2018). Predicting sudden stratospheric warming 2018 and its climate impacts with a multimodel ensemble. Geophys. Res. Lett., 45(24), 13538-13546. https://doi.org/10.1029/2018GL081091

King, A. D., Butler, A. H., Jucker, M., Earl, N. O., and Rudeva, I. (2019). Observed relationships between sudden stratospheric warmings and European climate extremes. J. Geophys. Res. Atmos., 124(24), 13943-13961. https://doi.org/10.1029/2019JD030480

Kozubek, M., Krizan, P., and Lastovicka, J. (2015). Northern Hemisphere stratospheric winds in higher midlatitudes: longitudinal distribution and long-term trends. Atmos. Chem. Phys., 15(4), 2203-2213. https://doi.org/10.5194/acp-15-2203-2015

Kuttippurath, J., and Nikulin, G. (2012). A comparative study of the major sudden stratospheric warmings in the Arctic winters 2003/2004-2009/2010. Atmos. Chem. Phys., 12(17), 8115-8129. https://doi.org/10.5194/acp-128115-2012

Lastovicka, J., Krizan, P., and Kozubek, M. (2018). Longitudinal structure of stationary planetary waves in the middle atmosphere-extraordinary years. Ann. Geophys., 36(1), 181-192. https://doi.org/10.5194/angeo-36-181-2018

Lee, S. H., Charlton-Perez, A. J., Furtado, J. C., and Woolnough, S. J. (2019). Abrupt stratospheric vortex weakening associated with North Atlantic anticyclonic wave breaking. J. Geophys. Res. Atmos., 124(15), 8563-8575. https://doi.org/10.1029/2019JD030940

Lee, S. H., and Butler, A. H. (2020). The 2018-2019 Arctic stratospheric polar vortex. Weather, 75(2), 52-57. https://doi.org/10.1002/wea.3643

Li, N., Luan, X. L., Lei, J. H., Bolaji, O. S., Owolabi, C., Chen, J. S., Xu, Z. W., Li, G. Z., and Ning, B. Q. (2020). Variations of mesospheric neutral winds and tides observed by a meteor radar chain over China during the 2013 sudden stratospheric warming. J. Geophys. Res. Space Phys., 125(5), e2019JA027443. https://doi.org/10.1029/2019JA027443

Liu, G. Q., Huang, W. G., Shen, H., Aa, E. C., Li, M. X., Liu, S. Q., and Luo, B. X. (2019). lonospheric response to the 2018 sudden stratospheric warming event at middle- and low-latitude stations over China sector. Space Wea., 17(8), 1230-1240. https://doi.org/10.1029/2019SW002160

Liu, S. M., Chen, Y. H., Rao, J., Cao, C., Li, S. Y., Ma, M. H., and Wang, Y. B. (2019). Parallel comparison of major sudden stratospheric warming events in 
CESM1-WACCM and CESM2-WACCM. Atmosphere, 10(11), 679. https://doi.org/10.3390/atmos10110679

Liu, Y., and Zhang, Y. L. (2014). Overview of the major 2012-2013 northern hemisphere stratospheric sudden warming: evolution and its association with surface weather. J. Meteor. Res., 28(4), 561-575. https://doi.org/10.1007/s13351-014-3065-Z

Lü, Z. Z., Li, F., Orsolini, Y. J., Gao, Y. Q., and He, S. P. (2020). Understanding of European cold extremes, sudden stratospheric warming, and Siberian snow accumulation in the Winter of 2017/18. J. Climate, 33(2), 527-545. https://doi.org/10.1175/JCLI-D-18-0861.1

Lu, X., Wu, H. N., Oberheide, J., Liu, H. L., and McInerney, J. M. (2018). Latitudinal double-peak structure of stationary planetary wave 1 in the austral winter middle atmosphere and its possible generation mechanism. J. Geophys. Res. Atmos., 123(20), 11551-11568. https://doi.org/10.1029/2018JD029172

Ma, Z., Gong, Y., Zhang, S. D., Zhou, Q. H., Huang, C. M., Huang, K. M., Yu, Y., Li, G. Z., Ning, B. Q., and Li, C. (2017). Responses of Quasi 2 day waves in the MLT region to the 2013 SSW revealed by a meteor radar chain. Geophys. Res. Lett., 44(18), 9142-9150. https://doi.org/10.1002/2017GL074597

Ma, Z., Gong, Y., Zhang, S. D., Zhou, Q. H., Huang, C. M., Huang, K. M., Dong, W. J., Li, G. Z., and Ning, B. Q. (2018). Study of mean wind variations and gravity wave forcing via a meteor radar chain and comparison with HWM-07 results. J. Geophys. Res. Atmos., 123(17), 9488-9501. https://doi.org/10.1029/2018JD028799

Ma, Z., Gong, Y., Zhang, S. D., Zhou, Q. H., Huang, C. M., Huang, K. M., Luo, J. H., $\mathrm{Yu}, \mathrm{Y}$., and Li, G. Z. (2020). Study of a quasi-4 day oscillation during the 2018/2019 SSW over Mohe, China. J. Geophys. Res. Space Phys.. https://doi.org/10.1029/2019JA027687

Manney, G. L., Schwartz, M. J., Krüger, K., Santee, M. L., Pawson, S., Lee, J. N., Daffer, W. H., Fuller, R. A., and Livesey, N. J. (2009). Aura Microwave Limb Sounder observations of dynamics and transport during the recordbreaking 2009 Arctic stratospheric major warming. Geophys. Res. Lett., 36(12), L12815. https://doi.org/10.1029/2009GL038586

Matsuno, T. (1971). A dynamical model of the stratospheric sudden warming. J. Atmos. Sci., 28(8), 1479-1494. https://doi.org/10.1175/1520-

0469(1971)028<1479:ADMOTS>2.0.CO;2
Mitchell, D. M., Gray, L. J., Anstey, J., Baldwin, M. P., and Charlton-Perez, A. J. (2013). The influence of stratospheric vortex displacements and splits on surface climate. J. Climate, 26(8), 2668-2682. https://doi.org/10.1175/JCLI-D12-00030.1

Nath, D., Chen, W., Zelin, C., Pogoreltsev, A. L., and Wei, K. (2016). Dynamics of 2013 Sudden Stratospheric Warming event and its impact on cold weather over Eurasia: Role of planetary wave reflection. Sci. Rep., 6, 24174. https://doi.org/10.1038/srep24174

Rao, J., Ren, R. C., Chen, H. S., Yu, Y. Y., and Zhou, Y. (2018). The stratospheric sudden warming event in February 2018 and its prediction by a climate system model. J. Geophys. Res. Atmos., 123(23), 13332-13345. https://doi.org/10.1029/2018JD028908

Rao, J., Ren, R. C., Chen, H. S., Liu, X. W., Yu, Y. Y., Hu, J. G., and Zhou, Y. (2019a). Predictability of stratospheric sudden warmings in the Beijing Climate Center Forecast System with statistical error corrections. J. Geophys. Res. Atmos., 124(15), 8385-8400. https://doi.org/10.1029/2019JD030900

Rao, J., Garfinkel, C. I., Chen, H. S., and White, I. P. (2019b). The 2019 New Year stratospheric sudden warming and its real-time predictions in multiple S2S models. J. Geophys. Res. Atmos., 124(21), 11155-11174. https://doi.org/10.1029/2019JD030826

Rao, J., Garfinkel, C. I., \&White, I. P. (2020). Predicting the downward and surface influence of the February 2018 and January 2019 sudden stratospheric warming events in subseasonal to seasonal (S2S) models. J. Geophys. Res. Atmos., 125(2), e2019JD031919. https://doi.org/10.1029/2019JD031919

Seviour, W. J. M., Mitchell, D. M., and Gray, L. J. (2013). A practical method to identify displaced and split stratospheric polar vortex events. Geophys. Res. Lett., 40(19), 5268-5273. https://doi.org/10.1002/grl.50927

Shi, C. H., Xu, T., Guo, D., and Pan, Z. T. (2017). Modulating effects of planetary wave 3 on a stratospheric sudden warming event in 2005. J. Atmos. Sci., 74(5), 1549-1559. https://doi.org/10.1175/JAS-D-16-0065.1

Xiong, J. G., Wan, W. X, Ding, F., Liu, L. B., Hu, L. H., and Yan, C. X. (2018). Two day wave traveling westward with wave number 1 during the sudden stratospheric warming in January 2017. J. Geophys. Res. Space Phys., 123(4), 3005-3013. https://doi.org/10.1002/2017JA025171 